Acta vet. scand. 1970, 11, 114-132.

From the Institute of Pharmacology and Toxicology, Royal Veterinary and Agricultural University, Copenhagen, Denmark.

\title{
RUMINAL METABOLISM OF DNOC AND DNBP*)
}

\author{
By \\ Arne Fröslie ${ }^{\star \star}$ and Ole Karlog
}

When organic nitro compounds are administered orally to ruminants, a reduction of nitro groups to amino groups by the activity of the rumen flora may influence the toxicity of the compounds. This is the case, for instance, with parathion, which in $\mathrm{mg} / \mathrm{kg}$ body weight is about five times less toxic in adult ruminants than in rats, because parathion becomes converted into aminoparathion in the rumen (Cook 1957, Andersen \& Karlog 1963). A corresponding reduction, in the rumen, of the herbicide 2,4-dichloro-4'-nitrodiphenoloxide was demonstrated by Gutenmann \& Lisk (1967). As regards the dinitrophenol derivatives 4,6-dinitro-o-cresol (DNOC) and 4,6-dinitro-2-sec.-butylphenol (DNBP, dinoseb) used in agriculture, mainly as herbicides, similar conditions would seem to apply. Harvey (1958) demonstrated a decomposition of DNOC in rumen fluid in vitro and assumed the formation of a 6-amino derivative, but did not succeed in isolating and identifying that metabolite. However, a considerably higher concentration of DNOC in the blood after intraperitoneal than after oral administration to ruminants supports his assumption that a significant reduction also takes place in the rumen in vivo.

* This study was carried out with financial support from the Novo Foundation, Copenhagen.

* * Address: National Veterinary Institute, Oslo 4, Norway. Fellowship granted by Landbruksdepartementet, Veterinærfondet, I. A. Lo's legat, and veterinærdirekt $\varnothing \mathrm{r}$ Niels Thorshaugs fond, Oslo. 
It is natural to put these observations in relation to the lower toxicity of DNOC in goats than in rats. LD50 for DNOC given orally to rats is $30 \mathrm{mg} / \mathrm{kg}$ and to goats $100 \mathrm{mg} / \mathrm{kg}$, and after five daily doses of $50 \mathrm{mg} / \mathrm{kg}$ goats show no signs of poisoning ( $\mathrm{Neg}$ herbon 1959).

In contrast, a possible reduction of DNBP in the rumen does not seem to have any decreasing effect on the toxicity, as oral administration of $25 \mathrm{mg} / \mathrm{kg}$ for 4 days caused fatal poisoning in sheep (Radeleff $\&$ Bushland 1960), whereas LD50 in rats is 37 $\mathrm{mg} / \mathrm{kg}$ (Negherbon). Since the degradation of DNBP by microorganisms in the soil is more difficult than the decomposition of DNOC (Jensen \& Lautrup-Larsen 1967), it was considered expedient to investigate whether differences in ruminal metabolism could be the reason why DNOC is tolerated better by ruminants than DNBP.

\section{MATERIAL AND METHODS}

\section{Reference substances}

2-methyl-4,6-dinitrophenol (4,6-dinitro-o-cresol; DNOG), m.p. $86^{\circ} \mathrm{C}$.

2-(1-methyl-n-propyl)-4,6-dinitrophenol (4,6-dinitro-2-sec.-butylphenol; DNBP, dinoseb), m.p. $40-41^{\circ} \mathrm{C}$.

2-methyl-4-nitro-6-aminophenol (6-amino-4-nitro-o-cresol; 6-ANOC), m.p. $170-175^{\circ} \mathrm{C}$.

2-(1-methyl-n-propyl)-4-nitro-6-aminophenol (6-amino-4-nitro2-sec.-butylphenol; 6-ANBP), m.p. $89-90^{\circ} \mathrm{C}$.

Both monoamino derivatives were produced from the corresponding dinitrophenols by the method described by Cazeneuve (1897) as modified by Bennett et al. (1946).

2-methyl-4,6-diaminophenol (4,6-diamino-o-cresol; DAOC).

2-(1-methyl-n-propyl)-4,6-diaminophenol (4,6-diamino-2-sec.butylphenol; DABP).

Both diamino compounds were made from the corresponding dinitrophenols by reduction with zinc and hydrochloric acid. These compounds were unstable and could not be isolated.

In vitro experiments. Rumen fluid was obtained from a cow via a permanent rumen fistula 2 hrs. after the morning feeding. Immediately after filtration through sterile gauze, $150 \mathrm{ml}$ of the fluid was transferred to a double-necked fermentation flask. After vigorous bubbling through the contents of the flask for 30 sec. with pure nitrogen, the flask was connected to a nitrogen 
reservoir. The addition and sampling were carried out in such a way that anaerobic conditions were maintained throughout the experimental period. The experiments were performed at $39^{\circ} \mathrm{C}$ $\pm 1^{\circ} \mathrm{C}$, and the compounds examined were added, dissolved in $4 \mathrm{ml}$ acetone and mixed with the contents of the flask by shaking.

A control experiment with heat-sterilized rumen fluid was performed with the same experimental set-up.

In the investigations of the influence of the initial concentration of DNOC and DNBP on the metabolic turnover, the rumen fluid was placed in a $50 \mathrm{ml}$ centrifuge tube which, after ventilation with nitrogen, was made airtight with parafilm.

In vivo experiments. The same cow was used for these experiments. Two experiments were made with DNOC at an interval of 2 weeks and two experiments with DNBP at an interval of 8 weeks. The dinitrophenols, dissolved in $150 \mathrm{ml}$ acetone, were administered through the rumen fistula in the foremost part of the rumen. The dinitrophenols and the rumen fluid were mixed manually. Rumen fluid and blood samples were taken for analysis simultaneously. During the experiments with DNOC the cow was fed $2 \mathrm{~kg}$ hay, $2 \mathrm{~kg}$ straw, $15 \mathrm{~kg}$ turnips and 11/2 kg rolled oats, while during the DNBP experiments it was given $12-15 \mathrm{~kg}$ lucerne, $2 \mathrm{~kg}$ straw and $1 \frac{1}{2} \mathrm{~kg}$ rolled oats. The oats were given as part of the morning feed, while the remainder of the fodder was distributed among two feeds.

\section{Analytical methods}

Qualitative. Thin layer chromatographic analysis was made by means of a modification of the method of Heyndrickx et al. (1964) on activated silica gel plates prepared with McIlvain's buffer, $\mathrm{pH}$ 6.5. The chromatograms were developed at $27^{\circ} \mathrm{C}$ with chloroform-methanol $(4+1)$. Spots that were visible in daylight and ultraviolet light were marked. The development process was carried out by means of ammonia vapour. Details of the sensitivity of the method, the relative Rf $_{\text {DNOC values and the colour }}$ reactions on development are shown in Table 1.

The qualitative and quantitative spectrophotometric analyses were made on automatically registering Beckman DB and Beckman DU 2 spectrophotometers, respectively. The spectra shown in Fig. 1 were used for identification. IR-spectrophotometry was also used for this purpose. 
T a b l e 1. Relative Rf-values, sensitivity in $\mu$ g and colours for DNOC, DNBP, 6-ANOC, 6-ANBP, DAOC and DABP on thin layer chromatograms.

\begin{tabular}{|c|c|c|c|c|}
\hline & $\mathrm{Rf}_{\mathrm{DNOC}}$ & $\begin{array}{l}\text { Lower } \\
\text { limit }\end{array}$ & $\begin{array}{c}\text { Colour on buffered } \\
\text { silicagel }\end{array}$ & $\begin{array}{c}\text { Colour after } \\
\text { detection with } \mathrm{NH}_{3}\end{array}$ \\
\hline DNOC & 1 & 0.5 & yellow & $\begin{array}{l}\text { yellow, increased } \\
\text { intensity }\end{array}$ \\
\hline DNBP & 1.1 & 0.5 & yellow & $\begin{array}{l}\text { yellow, increased } \\
\text { intensity }\end{array}$ \\
\hline 6-ANOC & $0.75-0.85$ & 0.5 & orange-yellow & orange \\
\hline 6-ANBP & $0.85-0.95$ & 0.5 & orange-yellow & orange \\
\hline DAOC & 0.25 & 1 & red-violet & red-violet \\
\hline DABP & 0.25 & 1 & red-violet & red-violet \\
\hline
\end{tabular}

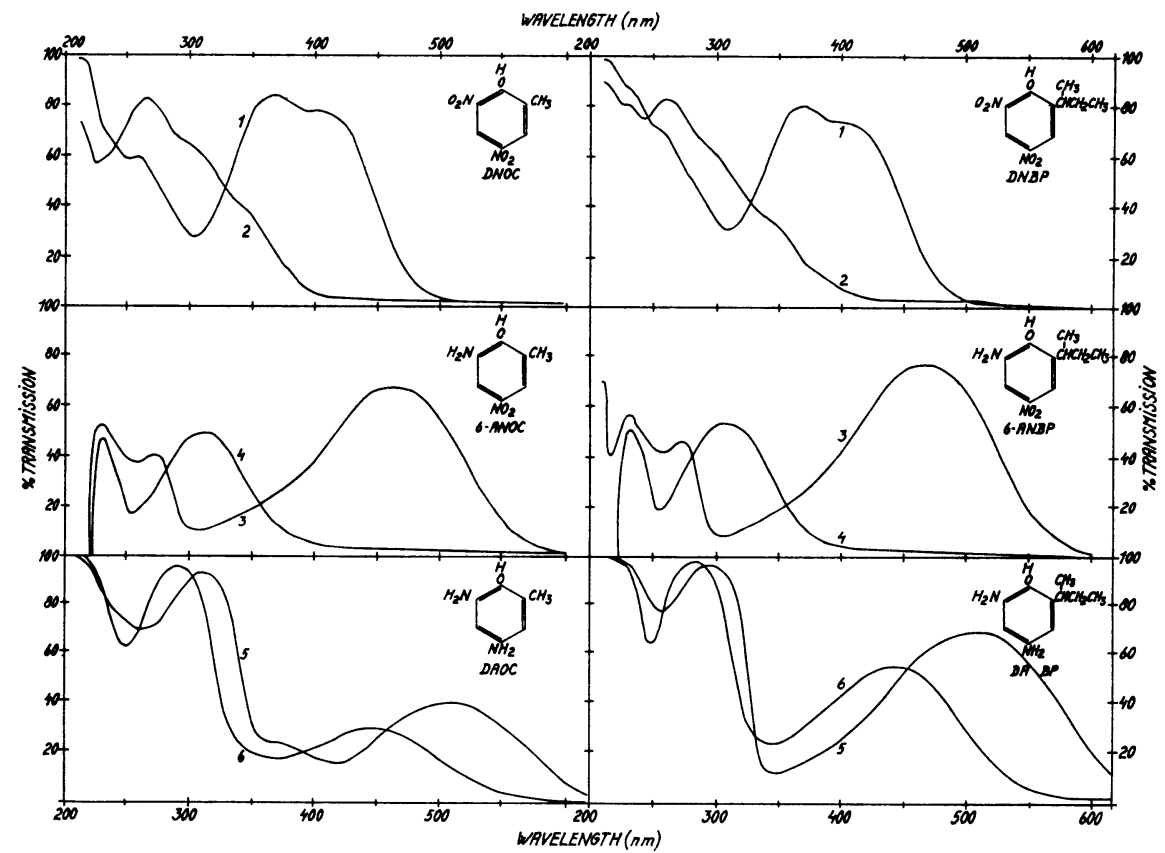

F i g u r e 1. Spectra of DNOC and DNBP and the metabolites 6-ANOC, DAOC, 6-ANBP and DABP: (1) dissolved in $0.1 \mathrm{M}$ methanolic sodium hydroxide, (2) $3 \mathrm{ml}$ of (1) $+150 \mu \mathrm{l} 5 \mathrm{M}$ hydrochloric acid, (3) dissolved in $0.1 \mathrm{M}$ sodium hydroxide, (4) $3 \mathrm{ml}$ of (3) $+150 \mu \mathrm{l} 5 \mathrm{M}$ hydrochloric acid, (5) and (6) diamino compounds as aminoquinonimides in acid and basic methanolic solution after elution on aluminium oxide column. 
Table 2. Absorption characteristics used in spectrophotometric determination of DNOC, DNBP, 6-ANOC, 6-ANBP, DAOC and DABP (the two latter as aminoquinonimides).

\begin{tabular}{lrrl}
\hline & $\lambda \max ^{\mathrm{m} \mu}$ & & Extinction coefficient \\
\hline DNOC & 400 & 11500 & \\
DNBP & 400 & 12500 & $\Delta \varepsilon$, difference in molar \\
6-ANOC & 460 & 14500 & extinction coefficient. \\
6-ANBP & 468 & 15700 & \\
\hline DAOC & 500 & 2650 & $\varepsilon$, molar extinction \\
DABP & 500 & 2600 & coefficient. \\
\hline
\end{tabular}

Quantitative. Elution and isolation were performed as follows: The specimens were added to the double volume of methanol and applied to an aluminium oxide column. The column was eluted with methanol, and the dinitrophenols removed quantitatively, while the monoamino derivatives were held back. These compounds were then eluted quantitatively with $0.1 \mathrm{~N}-\mathrm{NaOH}$. In the quantitative spectrophotometric analysis, use was made of the differences between the absorption of the individual compound in alkaline and acid solution thus eliminating almost completely the unspecific background absorption.

The diamino compounds were determined after oxidation with excess of potassium dichromate and subsequent measurement of the aminoquinonimides (Kehrmann \& Prager 1906). Standard curves were worked out as follows: $200 \mathrm{mg}$ of DNOC or DNBP was reduced quantitatively by means of zinc and hydrochloric acid. A series of dilutions was made from these solutions. To $4.00 \mathrm{ml}$ of these dilutions was added $4.00 \mathrm{ml}$ of $50 \%$ trichloracetic acid, $1.00 \mathrm{ml}$ of $1 \%$ potassium dichromate and $3.00 \mathrm{ml}$ of $1 \mathrm{M}$ hydrochloric acid. After $40 \mathrm{~min}$. standing, the extinction was read at $500 \mathrm{~m} \mu$ against blind specimens treated similarly. The data used in the quantitative spectrophotometric determinations are shown in Table 2.

In recovery experiments dinitrophenols and their mono- and diamino derivatives were added to rumen fluid in concentrations of $10-180 \mu \mathrm{g} / \mathrm{ml}$, and it was found that the simultaneous presence had no effect on the results of the analysis. 
Method of elution and isolation of the dinitrophenols and their metabolites

Rumen fluid. In order to stop momentarily the microbial decomposition in the rumen fluid, the following procedures were adopted:

A. $4.00 \mathrm{ml}$ of rumen specimen was transferred to a centrifuge tube containing $4.00 \mathrm{ml}$ of $50 \%$ trichloracetic acid.

B. $5.00 \mathrm{ml}$ of rumen specimen was transferred to a centrifuge tube containing $10.00 \mathrm{ml}$ of methanol.

Specimen $A$ was used for analysis for diamino compounds. Since these compounds are unstable, analysis was made immediately after the sample was taken. Centrifugation was carried out at $2000 \times \mathrm{g}$ for $10 \mathrm{~min} .6 .00 \mathrm{ml}$ of supernatant was transferred to a test tube and $1.00 \mathrm{ml}$ of $1 \%$ potassium dichromate solution was added and shaken. A suitable aliquot, 3-6 ml, was transferred to a $5 \mathrm{~g}$ aluminium oxide column and eluted quantitatively with $1 \mathrm{M}$ hydrochloric acid. The coloured fraction, consisting of the aminoquinonimides and the excess of potassium dichromate, was collected. After suitable dilution the concentration of diamino compounds was measured by spectrophotometry $40 \mathrm{~min}$. after addition of the potassium dichromate. A rumen sample taken immediately before the start of the experiment, but otherwise treated as described above, was used for correction of background absorption. Potassium dichromate solution diluted to the same volume as the fluid analysed was used as reference.

Specimen $B$ was used both directly for thin layer chromatographic analysis and for the quantitative determination of the dinitrophenols and their monoamino derivatives, as follows: The specimen was centrifuged $(2000 \times \mathrm{g}$ for $10 \mathrm{~min}$. $)$ and an aliquot transferred to a $10 \mathrm{~g}$ aluminium oxide column. The dinitrophenols were eluted with methanol and the yellow fraction was collected and diluted suitably with methanol, $2.0 \mathrm{ml}$ of $5 \mathrm{M}-\mathrm{NaOH}$ per $100 \mathrm{ml}$ final solution being added. The content of dinitrophenol was determined by spectrophotometric analyses as described above. The monoamino derivatives were then eluted quantitatively with $0.1 \mathrm{M}-\mathrm{NaOH}$. The coloured fraction was collected and diluted suitably with $0.1 \mathrm{M}-\mathrm{NaOH}$ and the content of monoamino derivative determined by spectrophotometric analysis. 
Plasma. The heparinized blood specimens were centrifuged $(2000 \times \mathrm{g}$ for $20 \mathrm{~min}$.) immediately after being taken. $5.00 \mathrm{ml}$ of plasma was transferred to a centrifuge tube containing 25.00 $\mathrm{ml}$ of methanol. After shaking and standing for $30 \mathrm{~min}$., centrifugation was again carried out, and $20.00 \mathrm{ml}$ of supernatant was transferred to a $50 \mathrm{ml}$ beaker. This aliquot, which corresponds to two-thirds of the specimen, was cautiously evaporated on water bath $\left(60^{\circ} \mathrm{C}\right)$ until $2-3 \mathrm{ml}$ remained. Two $\mathrm{ml}$ of methanol was added and the fluid transferred to a $5 \mathrm{~g}$ aluminium oxide column, after which the procedure was the same as mentioned under determination of dinitrophenols and monoamino derivatives in rumen fluid.

\section{RESULTS}

Effect of the initial concentration on the metabolism in vitro

As pointed out by Harvey (1958), strongly biologically active compounds such as DNOC can reduce the activity of the rumen flora and thus inhibit their own decomposition. In order to elucidate this aspect, a series of in vitro experiments was made in which the metabolism of the dinitrophenols in rumen fluid was measured by registration of the dinitrophenol concentration before and after incubation for 5 min. Fig. 2 shows the results of two sets of experiments in which comparison was made between the decomposition of DNOC and DNBP in identical rumen fluid samples. The reduced amount of DNOC or DNBP is set in relation to the initial concentrations in the medium. It will be seen that an inhibitory effect of DNOC does not occur until concentrations of almost $4 \times 10^{-3} \mathrm{M}$, while, as regards DNBP, inhibition begins at concentrations greater than $1 \times 10^{-3} \mathrm{M}$.

In vitro metabolism of DNOC. By incubating rumen fluid to which $300 \mu \mathrm{g}$ DNOC per $\mathrm{ml}\left(1.5 \times 10^{-3} \mathrm{M}\right)$ was added and taking specimens for analysis at intervals of a few min., thin layer chromatographic analysis showed that DNOC could only be recovered during the first $15 \mathrm{~min}$. after commencement of incubation. After about $10 \mathrm{~min}$. there was an increasing amount of 6-ANOC until at about $30 \mathrm{~min}$. after the start of the experiment. Then it decreased, and after about $120 \mathrm{~min}$. it could no longer be demonstrated. After incubation for about $1 \mathrm{hr}$., a spot could be seen on the chromatogram that resembled DAOC or the cor- 


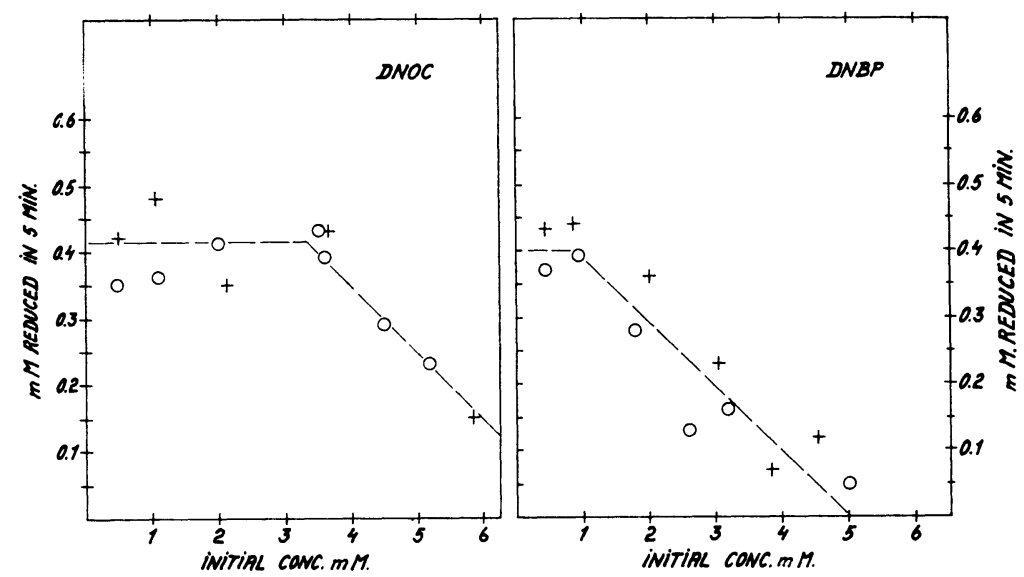

$\mathrm{Figure} 2$. Reduction of dinitrophenols in rumen fluid in relation to the initial concentration. Ordinate: Molar reduction of dinitrophenol per $5 \mathrm{~min}$. Abscissa: Molar initial concentration of dinitrophenols.

responding aminoquinonimide from the point of view of $\mathrm{Rf}$-value and colour. In specimens taken from 40 to $100 \mathrm{~min}$. after the start of the experiment, a pale yellow spot could also be seen almost following the liquid front. The compound in this spot was not identified. It gave no colour reaction after diazotization and coupling, and thus it can be excluded that the spot contained 2-methyl-4-amino-6-nitrophenol (Smith et al. 1953). A similar spot was observed in the specimens from the experiment on the decomposition of 6-ANOC, and it is therefore probable that the compound is an intermediate formed during the conversion of 6-ANOC to DAOC.

The metabolites demonstrated by thin layer chromatography were further identified by the absorption spectra of the compounds in the ultraviolet, visible and infrared ranges. However, it was not possible to elute enough of the unknown metabolite for such curves to be drawn.

Quantitative in vitro experiments. The contents of DNOC, 6-ANOC and DAOC were analysed quantitatively in four incubation experiments. The results of two of these are shown in Fig. 3. It will be seen that about 20 min. after the start of the experiment, it was no longer possible to demonstrate DNOC, while the maximum concentration of 6 -ANOC was reached in the course of the first 30 min., at which stage about $65 \%$ of the 


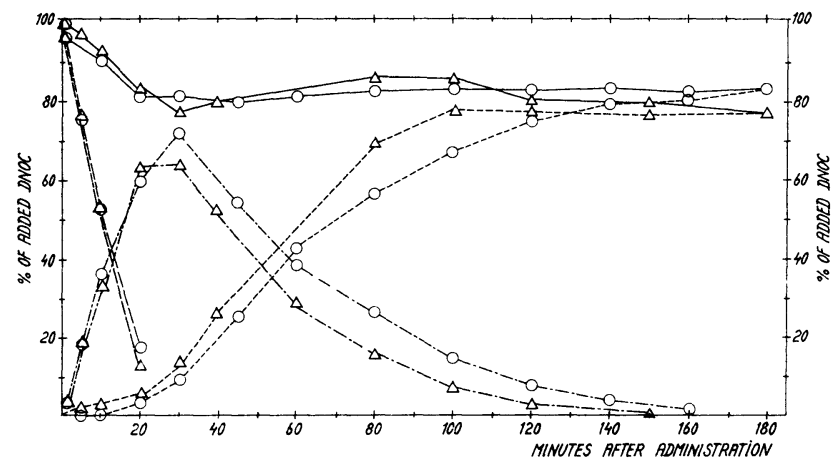

F i g u r e 3. In vitro metabolism of DNOC in rumen fluid. Symbols: Expt. 1: o; expt. 2: $\triangle$. DNOC - — , 6-ANOC - - - , DAOC -..., total amount recovered

DNOC added was 6-ANOC. Subsequently the concentration decreased, and after $150 \mathrm{~min}$. this compound could no longer be demonstrated. The concentration of DAOC increased during the first 2 hrs. of the experiment and remained constant during the rest of the observation period. The total amount of DNOC and metabolites which could be accounted for are also shown in Fig. 3. It will be seen that at the beginning of the experiment the amount decreased to $80 \%$ of the DNOC added and remained quite constant for the rest of the period, though there was a tendency to slightly poorer recovery between 40 and $60 \mathrm{~min}$. after the start of the experiment.

Fig. 4 shows the results of two experiments in which 6-ANOC was added to rumen fluid in a concentration corresponding to $300 \mu \mathrm{g} \mathrm{DNOC} / \mathrm{ml}$. It will be seen that the concentration of the monoamino compound decreased gradually and that after 2 hrs. it was no longer possible to demonstrate 6-ANOC. Concurrently, the concentration of DAOC increased, so that at the commencement of the experiment almost $100 \%$ of the amount added could be accounted for, but later in the period only between $82 \%$ and $94 \%$. 6-ANOC and DAOC could be demonstrated by thin layer chromatographic and spectrophotometric analyses, together with small amounts of a compound with the same characteristics as those of the unidentified metabolite described previously under the decomposition of DNOC.

A corresponding experiment on the stability of DAOC in active 


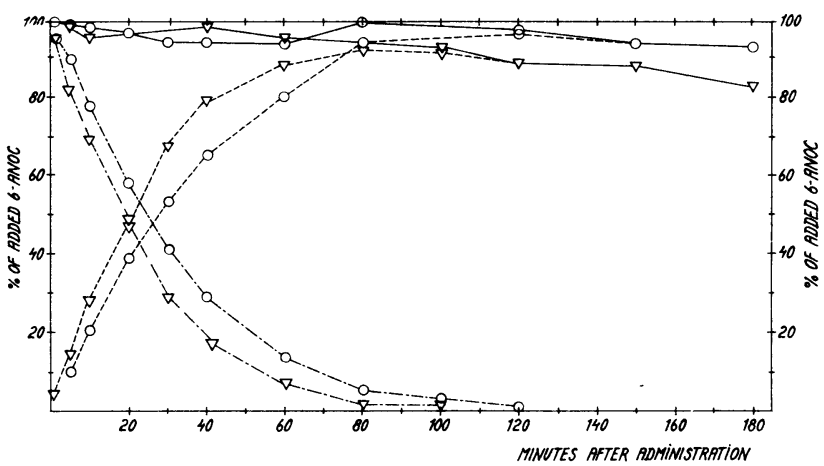

F i g u r e 4. In vitro metabolism of 6-ANOC in rumen fluid. Symbols: Expt. 1: 0; expt. 2: $\nabla .6$-ANOC $-.-\cdot-$, DAOC..-- , total amount recovered

rumen fluid showed that the DAOC concentration decreased gradually by about $3 \%$ per hr.

In a parallel experiment with two samples of identical rumen fluid, one of which was autoclaved in a closed container at $120^{\circ} \mathrm{C}$ for $20 \mathrm{~min}$. before the start of the experiment, it was found that the heat-treated specimen could not decompose the DNOC added.

In vitro metabolism of $D N B P$. Analogous to the experiments concerning the decomposition of DNOC, experiments were carried out to investigate the decomposition of DNBP with the addition of $300 \mathrm{\mu g} / \mathrm{ml}\left(1.25 \times 10^{-3} \mathrm{M}\right)$. Fig. 5 shows the results of one of these experiments. The somewhat slower metabolic turnover found in this experiment may, however, be caused by a lesser biological activity in the rumen fluid taken. Here again it was possible to account for between $80 \%$ and $85 \%$ of the compound. Fig. 6 shows the results of an experiment concerning decomposition of the metabolite 6-ANBP. The results were not different in principle from those obtained with the decomposition of 6-ANOC. Identification of the metabolites was carried out as described under the DNOC experiment, and a heat-treated specimen of rumen fluid was not able to decompose DNBP.

Ruminal metabolism of DNOC in vivo. Two experiments were performed on a cow weighing $475 \mathrm{~kg}$. DNOC, $12.5 \mathrm{~g}$ (corresponding to $26 \mathrm{mg} / \mathrm{kg}$ body weight) was administered into the rumen via the fistula. The cow showed no signs of intoxication. The 


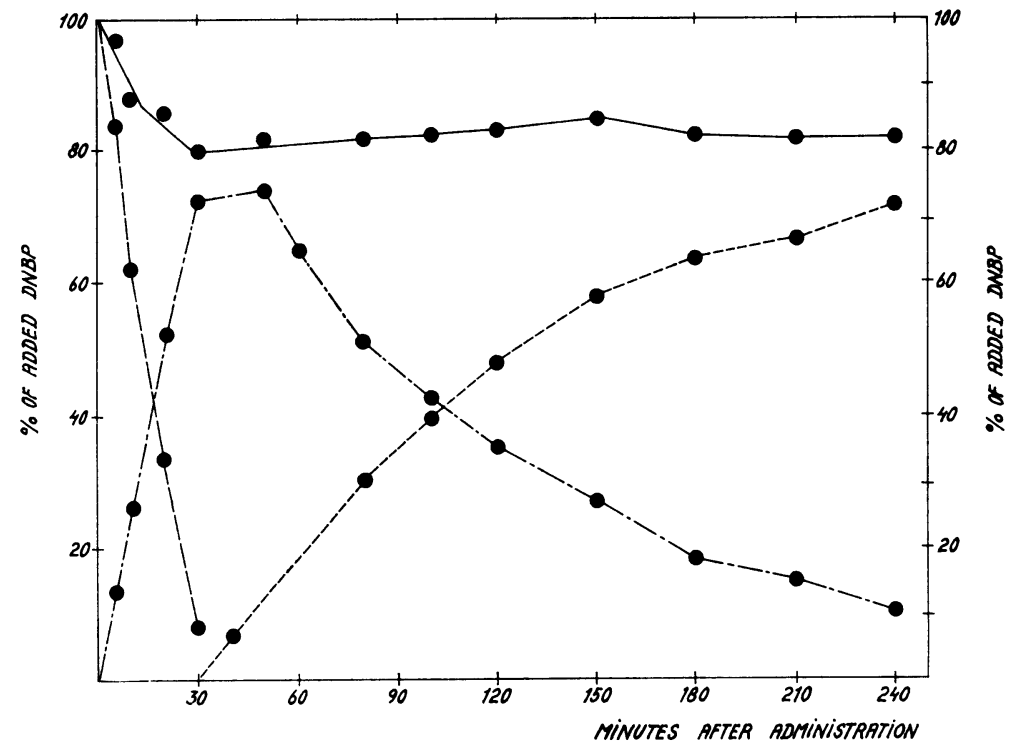

F i g u r e 5. In vitro metabolism of DNBP in rumen fluid. Symbols: DNBP — - , 6-ANBP - - - - DABP -..., total amount recovered -

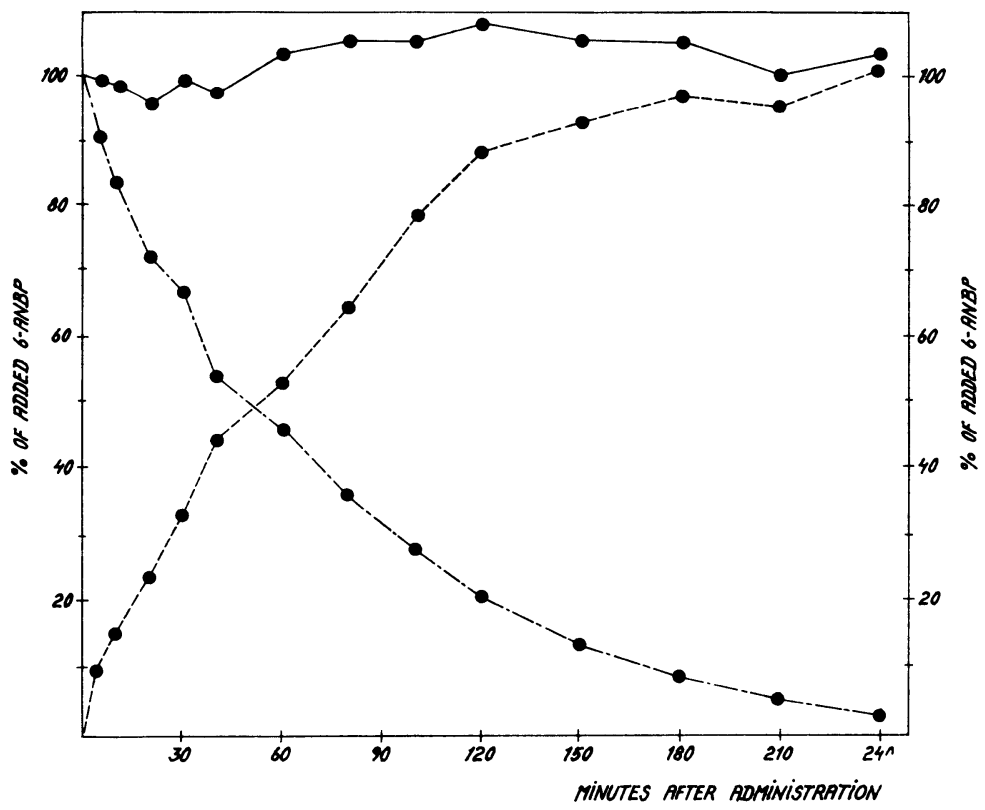

$\mathrm{F}$ i g u r e 6. In vitro metabolism of 6-ANBP in rumen fluid. Symbols: 6 -ANBP _...., DABP $\ldots . .$, , total amount recovered 
T a b l e 3. Metabolism of DNOC in rumen in vivo after administration of $12.5 \mathrm{~g}$ DNOC via rumen fistula (two experiments $\mathrm{A}, \mathrm{B}$ in the same cow).

\begin{tabular}{lccccccccc}
\hline & \multicolumn{8}{c}{ Time after administration in hours } \\
\cline { 3 - 9 } & & $1 / 12$ & $1 / 4$ & $1 / 2$ & 1 & 2 & 4 & 8 & 24 \\
\hline Conc. of DNOC & A & 3.0 & 0 & 0 & - & - & - & - & - \\
$\mu \mathrm{g} / \mathrm{ml}$ & B & 8.3 & 0 & 0 & - & - & - & - & - \\
Conc. of 6 -ANOC & A & 24 & 12 & 3.3 & 0 & - & - & - & - \\
$\mu \mathrm{g} / \mathrm{ml}$ & B & 16 & 15 & 4.0 & 2.0 & 0 & - & - & - \\
Conc. of DAOC & A & 9.0 & 44 & 76 & 77 & 42 & 21 & 16 & 0 \\
$\mu \mathrm{g} / \mathrm{ml}$ & B & 6.0 & 19 & 34 & 44 & 26 & 10 & 0 & 0 \\
\hline
\end{tabular}

pulse and temperature were within the normal range throughout the observation period, the pulse being 70-80 and the temperature $38-39^{\circ} \mathrm{C}$, and the animal had normal appetite. From about $30 \mathrm{~min}$. after the administration of DNOC the urine turned brown, and this discoloration could be seen for the next 24 hrs. Analysis of the rumen fluid specimens showed the same metabolites as in the in vitro experiments, but there were greater quantitative differences. DNOC could only be demonstrated in the rumen fluid during the first $10 \mathrm{~min}$. of the experiment, while small concentrations of 6-ANOC were found during the first hr. The maximum concentration of DAOC was obtained in the course of $30 \mathrm{~min}$.$1 \mathrm{hr}$., and 6-8 hrs. after the start of the experiment the compound was demonstrable neither in the qualitative nor the quantitative analyses (see Table 3 ).

Absorption of DNOC and metabolites. Analysis of blood plasma taken during the experiments showed DNOC 5 min. after the start of the experiment, reaching its maximum concentration of $20-25 \mu \mathrm{g} / \mathrm{ml}$ plasma in the course of the first $15 \mathrm{~min}$. After this the concentration fell slowly and after 1 week it had reached values which could no longer be determined. Following acid hydrolysis performed by heating the methanolprecipitated plasma specimens, no increase in the DNOC content could be seen, thus indicating that conjugated DNOC was probably not present.

6-ANOC was demonstrated only after acid hydrolysis of plasma specimens, which corresponds to the finding that unconjugated 6-ANOC was present only in a concentration of $\max .0 .1 \mu \mathrm{g} / \mathrm{ml}$ 
plasma. After acid hydrolysis, 6-ANOC was found in all specimens during the first 2 hrs. of experiment, with a maximum value of up to $7 \mu \mathrm{g} 6-\mathrm{ANOC} / \mathrm{ml}$ after about $30 \mathrm{~min}$. Neither before nor after hydrolysis was DAOC demonstrated in plasma by thin layer chromatographic analysis. No DNOC could be demonstrated in the ultrafiltrate of plasma after filtration through cellophane membrane by the method described by Poulsen (1956). Therefore, with the sensitivity of the analytical method, at most 1-2\% of the DNOC present could be found free in the water phase of the plasma.

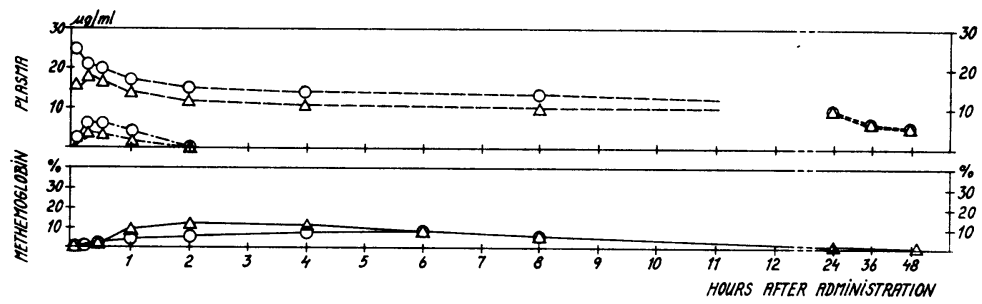

F i g u r e 7. In vivo experiments with DNOC. Concentrations of DNOC and 6-ANOC in blood plasma, and methaemoglobin percentage. Symbols: Expt. 1: o; expi. 2: $\triangle$. DNOC -..., 6-ANOC _.-.- , methaemoglobin

Methaemoglobin determination according to the method described by Stewart \& Stolman (1961) on the blood samples taken showed a methaemoglobin content which reached a maximum of $12 \%$ during the first 2-4 hrs. and was involuted in the course of the first 24 hrs. No haemolysis was observed. Fig. 7 shows the results obtained.

Ruminal metabolism of DNBP in vivo. Two experiments were performed in which $15 \mathrm{~g}$ of DNBP was administered into the rumen in the same cow as used for the experiment with DNOC. This dose, which corresponds in mol. to the dose of DNOC given, evoked acute symptoms of toxication, with strong increase in the pulse frequence and total anorexia. In the first experiment, the condition was critical for $1 \frac{1 / 2}{2}$ days after administration, with an almost unrecordable pulse frequency of $120-130$, normal body temperature but subnormal skin temperature, and muscular fibrillation. There was no improvement until the third day, but the pulse and appetite gradually became normal again during the next 2 weeks. In the second experiment, the situation was less 
T a b l e 4. Metabolism of DNBP in rumen in vivo after administration of $15.0 \mathrm{~g}$ DNBP via rumen fistula (two experiments $A, B$ in the same cow).

\begin{tabular}{lrrrrrrrrrrr}
\hline & \multicolumn{10}{c}{ Time after administration in hours } \\
\cline { 2 - 11 } & & $1 / 12$ & $1 / 4$ & $1 / 2$ & 1 & 2 & 4 & 6 & 11 & 24 \\
\hline Conc. of DNBP & A & 146 & 15 & 0 & - & - & - & - & - & - \\
$\mu \mathrm{g} / \mathrm{ml}$ & B & 228 & 164 & 0 & - & - & - & - & - & - \\
Conc. of 6-ANBP & A & 18 & 33 & 13 & 7 & 0 & - & - & - & - \\
$\mu \mathrm{g} / \mathrm{ml}$ & B & 36 & 154 & 76 & 13 & 0 & - & - & - & - \\
Conc. of DABP & A & 0 & 7 & 22 & 52 & 44 & 28 & 10 & - & 0 \\
$\mu \mathrm{g} / \mathrm{ml}$ & B & 0 & 5 & 17 & 33 & 56 & 43 & 28 & 5 & 0 \\
\hline
\end{tabular}

drastic, but also here the pulse was weak with a frequency of 120 - 130. In the DNBP experiment a strong reddish-brown urine was observed. Analysis of the rumen fluid specimens revealed the same metabolites as in the in vitro experiments but again with quantitative differences (see Table 4).

Absorption of DNBP and metabolites in blood plasma. Five min. after administration, DNBP could be found in plasma with maximum values not exceeding 5-10 $\mathrm{g} / \mathrm{ml}$. The elimination of DNBP took place very slowly. Ten days after administration $1-2 \mu \mathrm{g} / \mathrm{ml}$ plasma could still be demonstrated. Conjugated DNBP could not be found in plasma after acid hydrolysis and, as in the case of DNOC, all the DNBP was found to be bound to the plasma proteins. Maximum concentrations of 6-ANBP of up to $10 \mu \mathrm{g} / \mathrm{ml}$ plasma were reached in the course of $30 \mathrm{~min}$. - $1 \mathrm{hr}$., after which the concentration fell until $6 \mathrm{hrs}$. later, when it had reached values that were no longer measurable. 6-ANBP was only demonstrated unconjugated in plasma, in contrast to what was found

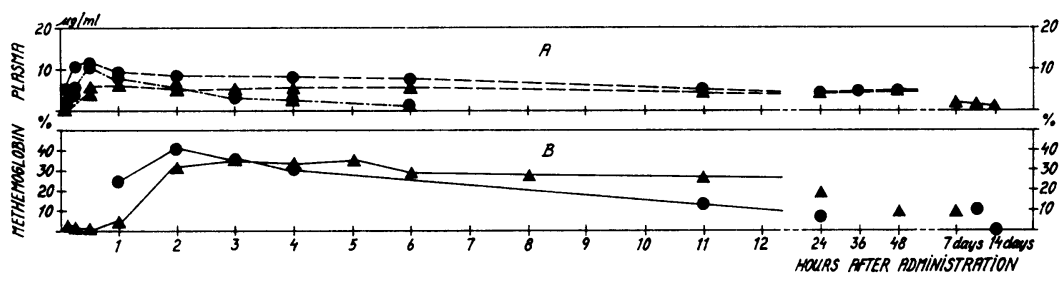

F i g u r e 8. In vivo experiment with DNBP. Concentrations of DNBP and 6-ANBP in blood plasma, and methaemoglobin percentage. Symbols: Expt. 1: •; expt. 2: $\triangle$. DNBP ...., 6-ANBP -.-.- , methaemoglobin 
with 6-ANOC. Neither before nor after hydrolysis DABP could be demonstrated in plasma by thin layer chromatographic analysis.

Two to four hrs. after the start of the experiment $30 \%-40 \%$ methaemologin was found. In both DNBP experiments the methaemoglobinaemia persisted and after 10 days a methaemoglobin percentage of 10 could still be demonstrated. After 14 days methaemoglobin could not be detected. Also haemolysis was seen and persisted for several days. The results can be seen in Fig. 8 .

\section{DISCUSSION}

The metabolism of DNOC in non-ruminants was examined in rabibts by Smith et al. (1953) who, in urine samples found 6-acetamido-4-nitro-o-cresol to be the principal metabolite while only traces of 4-amino-6-nitro-o-cresol was detected. Truhaut \& de Lavaur (1967) demonstrated 6-amino-4-nitro-o-cresol both in urine and in kidney, liver and brain tissue from rabbits in connection with the administration of DNOC, while the blood contained only the unchanged compound. According to Rahn's (1961) investigations DNBP is not reduced to amino compounds in rabbits, rats or guinea-pigs.

With the knowledge that microorganisms from soil can reduce aromatic nitro compounds to the corresponding arylamines (Madhosingh 1961, Takahashi et al. 1963, Tewfik \& Evans 1966), it might be possible that the mixed microflora in the rumen could effect a similar reduction of DNOC and DNBP. As first assumed by Harvey (1958), this is in fact the case, and the rapid process involves primary reduction of the nitro group in ortho position.

As shown in this paper the reduction did not take place in heat-sterilized rumen fluid, and the microbial induced conversion was inhibited by high initial concentrations. Under the anaerobic conditions existing in the rumen, the conversion goes on and involves further the reduction of the nitro group in the para position, so that in the in vitro experiments about $85 \%$ of the amount of dinitro compounds added could finally be recovered as diamino derivatives.

The in vivo experiments showed a similar rapid metabolism in the rumen fluid, but analysis of blood plasma demonstrated only the dinitro and monoamino compounds. This is presumably due to the fact that the diamino compounds are very labile at the oxygen pressure found in the blood and that they undergo a 
destruction similar to that observed in atmospheric air for other aminophenols (Rasmussen 1955).

After absorption both DNOC and DNBP were to a great extent bound to plasma proteins, resembling the $95 \%$ protein binding of DNOC in humans found by King \& Harvey (1953b). Elimination, determined by a decrease in the concentrations in plasma of both dinitro compounds, took place slowly as described in other animals and in man (King \& Harvey 1953a, 1953b, 1954; Lawford et al. 1954; Harvey 1958) and in agreement with the observation by St. John, jr. et al. (1965) of a slow renal excretion of DNBP in a cow.

The two 6-amino derivatives behaved differently in blood plasma. While 6-amino-4-nitro-o-cresol (6-ANOC) could only be demonstrated after acid hydrolysis and must therefore occur in conjugated form, 6-amino-4-nitro-sec.-butylphenol (6-ANBP) was present in uncoupled state. Furthermore, it was observed that the plasma concentration of 6-ANBP persisted longer than the concentration of 6-ANOC.

If it is attempted, on the basis of the results obtained, to draw conclusions concerning the comparatively low toxicity of DNOC for ruminants, the fact that identical doses of DNOC give much lower concentration in the blood of cattle, goats and sheep than in rats and rabbits (Harvey) can be explained by the extensive reduction of the compound in the rumen. Thus, much larger doses are required in ruminants to give "critical" concentrations of $40 \mu \mathrm{g} / \mathrm{ml}$ DNOC and more (Harvey).

The difference found in the toxicity of DNOG and DNBP in ruminants might be due to the fact that DNBP inhibits its own reduction in the rumen at a concentration level about three times lower than DNOC. However, this should be reflected in a considerably higher concentration of DNBP in blood plasma, and this was not the case. Thus, as the rate of metabolic turnover in the rumen did not differ significantly between the two dinitrophenols, our working hypothesis was not proved.

The two 6-amino metabolites and the methaemoglobinaemia and haemolysis observed are much more relevant. As a number of other aminophenols, both these compounds form methaemoglobin in vitro (own observations). In vivo, however, 6-ANBP occurred freely in plasma, while 6-ANOC was conjugated, presumably as an acetyl and/or glucoronide derivative as found by Smith et al. in rabbits. This conjugation seems to reduce the 
reactivity of the compound since methaemoglobinaemia was considerable after administration of DNBP and the cow was markedly affected by the treatment, whereas the same dose of DNOC did not provoke symptoms and only slight methaemoglobinaemia. There were no signs of the hyperthermia, strongly intensified respiration and sweating which are characteristic of poisoning with dinitrophenols, but cyanosis and anorexia were observed. Further investigations are necessary to verify whether the ability of ruminants to metabolize DNBP is a two-edged sword that can lead to intoxication due to methaemoglobinaemia produced by the metabolite 6-ANBP in unconjugated state.

\section{REFERENCES}

Andersen, A.-M. \& O. Karlog: Elimination of parathion in cows after oral and dermal administration. Acta vet. scand. 1963, 4, 156169.

Bennett, S. H., H. G. H. Kearns, H. Martin \& R. L. Wain: The use of toxic polynitro derivatives in pest control. III. The stability of dinitro-o-cresol in compounded products. Ann. appl. Biol. 1946, $13,396-400$.

Cazeneuve, M. P.: Sur quelques sels et quelques dérivés de l'orthocrésoldinitré. (On some salts and some derivatives of dinitro-ocresol). Bull. Soc. chim. Fr. 1897, 17, 204-206.

Cook, J. W.: In vitro destruction of some organophosphate pesticides by bovine rumen fluid. J. Agric. Food Chem. 1957, 5, 859-863.

Gutenmann, W. H. \& D. J. Lisk: Metabolism of TOK herbicide in the dairy cow. J. Dairy Sci. 1967, 50, 1516-1518.

Harvey, D. G.: Some aspects of the metabolism of 4,6-dinitro-o-cresol (DNC) by the ruminant. J. comp. Path. 1958, 68, 54-63.

Heyndrickx, A., R. Maes \& F. Tyberghein: Fatal intoxication by man due to dinitro-o-cresol (DNOC) and dinitrobutylphenol (DNBP). Mededel. Landbouwhogeschool, Gent 1964, 29, 1189-1197.

Jensen, H. L. \& G. Lautrup-Larsen: Microorganisms that decompose nitro-aromatic compounds, with special reference to dinitro-ocresol. Acta agric. scand. 1967, 17, 115-126.

St. John, jr., L. E., J. W. Ammering, D. G. Wagner, R. G. Warner \& D. J. Lisk: Fate of 4,6-dinitro-2-isobutylphenol, 2-chloro-4,6-bis(ethylamino)-S-triazine, and pentachloronitrobenzene in the dairy cow. J. Dairy Sci. 1965, 48, 502-503.

Kehrmann, F. \& H. Prager: Oxydation der Diaminophenole. (Oxydation of the diaminophenols). Ber. dtsch. chem. Ges. 1906, 39, $3437-3441$.

King, E. \& D. G. Harvey: Some observations on the absorption and excretion of 4,6-dinitro-o-cresol (DNOC). 1. Blood dinitro-ocresol levels in the rat and the rabbit following different methods of absorption. Biochem. J. 1953a, 53, 185-195. 
King, E. \& D. G. Harvey: Some observations on the absorption and excretion of 4,6-dinitro-o-cresol. 2. The elimination of 4,6-dinitro-o-cresol by man and by animals. Biochem. J. 1953b, 53, $196-200$.

King, E. \& D. G. Harvey: On the metabolism of some aromatic nitrocompounds by different species of animal. Part I. Some factors influencing the elimination of 4,6-dinitro-o-cresol from the blood of the rat. J. Pharm. Pharmacol. 1954, 6, 529-533.

Lawford, D. J., E. King \& D. G. Harvey: On the metabolism of some aromatic nitrocompounds by different species of animal. Part II. The elimination of various nitrocompounds from the blood of different species of animal. J. Pharm. Pharmacol. 1954, 6, $619-624$.

Madhosingh, C.: The metabolic detoxication of 2,4-dinitrophenol by Fusarium oxysporum. Canad. J. Microbiol. 1961, 7, 553-567.

Negherbon, W. O.: Handbook of 'Toxicology, vol. III. Insecticides. W. B. Saunders, London 1959, p. 289-297.

Poulsen, E.: Renale clearanceunders $\varnothing$ gelser hos køer. (Renal clearances in cows). Thesis, København 1956, p. 42-44.

Radeleff, R. D. \& R. C. Bushland: The toxicity of pesticides for livestock. USDA 1960, ARS 20-9, 134-160.

Rahn, H.-W.: Über den papierchromatographischen Nachweis toxikologisch wichtiger Nitroverbindungen und ihrer im Stoffwechsel entstehenden Abbauprodukte. (Paper-chromatographic detection of important toxic nitrocompounds and their metabolic products). Arch. exp. Path. Pharmakol. 1961, 241, 521.

Rasmussen, H. B.: Lærebog i organisk kemi. (Textbook in organic chemistry). Dansk Farmaceutforening 3. Ed. København 1955, p. 578.

Smith, J. N., R. H. Smithies \& R. T. Williams: Studies in detoxication. 48. Urinary metabolites of 4,6-dinitro-o-cresol in the rabbit. Biochem. J. 1953, 54, 225-230.

Stewart, C. P. \& A. Stolman: Toxicology. Mechanisms and Analytical Methods. Vol. II, Acad. Press, London 1961, p. 788-789.

Takahashi, H., S. Taniguchi \& F. Egami: Inorganic Nitrogen Compounds: Distribution and Metabolism (Appendix). In Comparative Biochemistry, ed. Florkin \& Mason. V. Acad. Press, New York and London 1963, p. 185-189.

Tewfik, M. S. \& W. C. Evans: The metabolism of 3,5-dinitro-o-cresol (DNOC) by soil microorganisms. Biochem. J. 1966, 99, 31 P.

Truhaut, R. \& E. de Lavaur: Étude du métabolisme du dinitro-4,6orthocrésol chez le lapin. (Studies on the metabolism of 4,6dinitro-o-cresol in the rabbit). C. R. Acad. Sci. (Paris) Sér. D. 1967, 264, 1937-1940. 


\section{SUMMARY}

The metabolism of DNOC and DNBP in rumen fluid was examined in vitro after elaboration of analytical methods for quantitative determination of dinitrophenols, their 6-amino derivative and diaminophenols. It was shown that, under anaerobic conditions, the dinitrophenols were rapidly converted into 6 -amino derivatives, which successively were reduced to diamino compounds. Reduction did not take place in heat-sterilized rumen specimens, and the metabolism was inhibited by high initial concentrations of the dinitro compounds in the rumen fluid $\left(1-4 \times 10^{-3} \mathrm{M}\right)$.

In vivo experiments were performed for determination of the concentrations of the dinitrophenols and their metabolites in rumen fluid and blood plasma in a cow. Ruminal metabolism was rapid like in vitro, and the parent compounds were reduced in $10-30 \mathrm{~min}$. The 6 -amino derivatives persisted in the rumen fluid for $1 \mathrm{hr}$., and thereafter only diaminophenols could be detected for another 8-10 hrs. At least $95 \%$ of the absorbed DNOC or DNBP were bound to plasma proteins. 6-amino-4-nitro-o-cresol was found in plasma exclusively in conjugated form, while 6-amino-4-nitro-sec.-butylphenol was free. The diamino compounds were not demonstrated in blood plasma.

Severe methaemoglobinaemia and haemolysis were seen after administration of DNBP. The difference in toxicity for ruminants between the two dinitrophenols is discussed on the basis of the observations reported pointing at the unconjugated 6-amino-4-nitro-sec.butylphenol as a potent inducer of methaemoglobinaemia.

\section{SAMMENDRAG}

Metabolisme af DNOC og DNBP $i$ vommen.

Metabolismen af DNOC og DNBP i vomsaft er unders $\varnothing$ gt in vitro efter udarbejdelse af analysemetoder til kvantitativ bestemmelse af dinitrofenolerne, deres 6-aminoderivater samt diaminofenolerne. Det er vist, at dinitrofenolerne under anaerobe betingelser hastigt omdannes til 6-aminoderivaterne, som sluttelig reduceres til diaminoforbindelserne. Reduktionerne finder ikke sted $\mathrm{i}$ varmesteriliserede vomprøver, og metabolismen hæmmes af høje initialkoncentrationer af dinitroforbindelserne $\mathrm{i}$ vomsaften.

I fors $\varnothing \mathrm{g}$ in vivo er koncentrationerne af dinitrofenolerne og deres metabolitter bestemt i vomsaft og i blodplasma. Såvel DNOG som DNBP bindes for mindst 95 procents vedkommende til plasmaproteiner. 6-amino-4-nitro-o-kresol findes udelukkende i konjugeret form i plasma, medens 6-amino-4-nitrobutylfenol findes frit. Diaminoforbindelserne er ikke påvist $\mathrm{i}$ blodplasma.

Der konstateredes specielt efter indgift af DNBP methæmoglobinæmi. Forskellen i toksiciteten af de to dinitrofenoler for drøvtyggere diskuteres på grundlag af de beskrevne iagttagelser. 